\title{
Who is not comfortable with the term "palliative care"-patient, family, or surgeon?
}

\author{
Shunichi Nakagawa, MD, ${ }^{\mathrm{a}}$ May Hua, MD, MSc, ${ }^{\mathrm{b}}$ and Hiroo Takayama, MD, PhD
}

Palliative care is an approach that improves quality of life for patients and their families facing life-threatening illness through prevention and relief of suffering. ${ }^{1}$ It helps reduce symptom burden, addresses psychologic and spiritual distress, provides support to both patient and family, and assists in establishing goals of care through difficult communications. It is interdisciplinary care and is offered concurrently with other life-prolonging measures, such as cardiothoracic surgery.

In his article in this issue of the Journal, Katz ${ }^{2}$ emphasizes the importance of this interdisciplinary care in cardiothoracic intensive care unit and suggests that the term "supportive care" be used instead of "palliative care" to allow patients, families, and providers to focus on recovery as a primary goal of cardiothoracic surgery. Indeed, a study in an academic cancer center showed that the name change from "palliative care" to "supportive care" was associated with more and earlier referrals.

Acknowledging the suggestion by Katz, ${ }^{2}$ we would like to raise the point that recovery and palliation are not mutually exclusive. Palliative care is not synonymous with endof-life care; rather, it is inclusive of both supportive and end-of-life care by definition. Regardless of the underlying disease (cancer or cardiothoracic surgery) or the trajectory of illness (recovering or deteriorating), as long as a patient's suffering is serious enough, it has to be addressed. Furthermore, the primary goal of some surgeries may be palliative in nature, because many patients choose to undergo surgery to improve their daily symptoms and quality of life (eg, ventricular assist devices, valve repairs). For these patients, "recovery" may be measured by how "palliated" their symptoms are.

Importantly, those who feel uncomfortable with the term "palliative care" may be cardiothoracic surgeons, rather than patients or families. A study in pediatrics showed

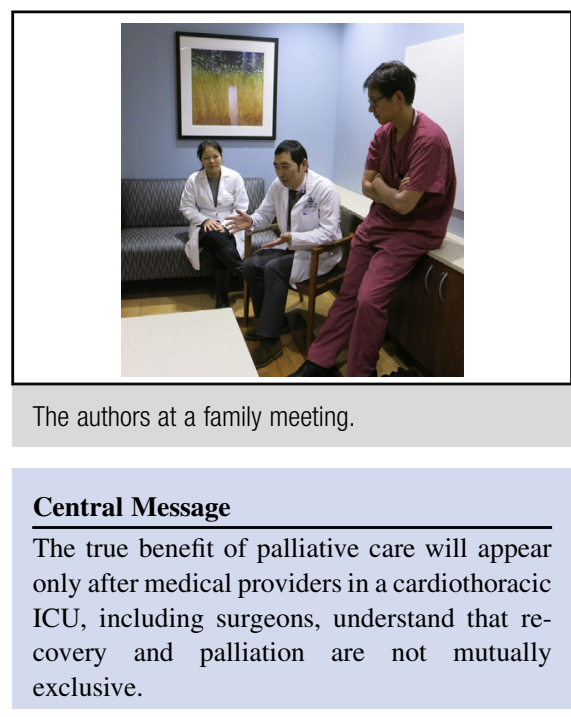

See Article page 2030. that although parents initially responded more favorably to the term "supportive care" than to the term "palliative care," the difference disappeared after they received proper explanation. ${ }^{4}$ The current challenge in cardiothoracic surgery appears similar to that in oncology 10 years ago, when many oncologists felt uncomfortable making a referral to palliative care. ${ }^{5}$ Now, after multiple studies have showed the benefit of palliative care, including improved survival, ${ }^{6,7}$ recent clinical guidelines from the American Society of Clinical Oncology recommend early incorporation of "palliative care" with active treatment as the standard of care.

The use of the term "supportive care" might help open the door to more and earlier integration of this patientcentered interdisciplinary approach to care for our cardiothoracic surgical patients. Its true benefit, however, will appear only after cardiothoracic intensive care unit care providers, including surgeons and intensivists, understand and trust the importance of such therapy. This requires a process of educating providers, which needs to be supported by rigorous research on the benefits of palliative care in the cardiothoracic intensive care unit. Katz ${ }^{2}$ provides a valuable perspective on a very important yet underappreciated therapy through which we can improve the care for our patients and families at their most vulnerable moment. 


\section{References}

1. World Health Organization. WHO definition of palliative care. Available at: http://www.who.int/cancer/palliative/definition/en/. Accessed February 1, 2018 .

2. Katz N. The term "supportive care" is preferable to "palliative care" for consults in the cardiothoracic ICU. J Thorac Cardiovasc Surg. 2018;155: 2030-1.

3. Dalal S, Palla S, Hui D, Nguyen L, Chacko R, Li Z, et al. Association between a name change from palliative to supportive care and the timing of patient referrals at a comprehensive cancer center. Oncologist. 2011;16:105-11.

4. Morstad Boldt A, Yusuf F, Himelstein BP. Perceptions of the term palliative care. J Palliat Med. 2006;9:1128-36.

5. Fadul N, Elsayem A, Palmer J, Del Fabbro E, Swint K, Li Z, et al. Supportive versus palliative care: what's in a name?: a survey of medical oncologists and midlevel providers at a comprehensive cancer center. Cancer. 2009;115:2013-21.

6. Temel JS, Greer JA, Muzikansky A, Gallagher ER, Admane S, Jackson VA, et al Early palliative care for patients with metastatic non-small-cell lung cancer. $N$ Engl J Med. 2010;363:733-42.

7. Bakitas MA, Tosteson TD, Li Z, Lyons KD, Hull JG, Li Z, et al. Early versus delayed initiation of concurrent palliative oncology care: patient outcomes in the ENABLE III randomized controlled trial. J Clin Oncol. 2015;33:1438-45.

8. Ferrell BR, Temel JS, Temin S, Alesi ER, Balboni TA, Basch EM, et al. Integration of palliative care into standard oncology care: American Society of Clinical Oncology clinical practice guideline update. J Clin Oncol. 2017;35:96-112. 